This is an electronic reprint of the original article. This reprint may differ from the original in pagination and typographic detail.

Author(s): Lähdesmäki, Tuuli; Heynderickx, Priscilla C.C.A.; Wagener, Albin; Dieltjens, Sylvain M.F.

Title: $\quad$ Negations and negativity as linguistic devices in policy discourse of intercultural cities

Year: $\quad 2015$

Version:

Please cite the original version:

Lähdesmäki, T., Heynderickx, P. C., Wagener, A., \& Dieltjens, S. M. (2015). Negations and negativity as linguistic devices in policy discourse of intercultural cities. Journal of Multicultural Discourses, 10(3), 332-348.

https://doi.org/10.1080/17447143.2015.1067220

All material supplied via JYX is protected by copyright and other intellectual property rights, and duplication or sale of all or part of any of the repository collections is not permitted, except that material may be duplicated by you for your research use or educational purposes in electronic or print form. You must obtain permission for any other use. Electronic or print copies may not be offered, whether for sale or otherwise to anyone who is not an authorised user. 


\title{
Negations and Negativity as Linguistic Devices in Policy Discourse of Intercultural Cities
}

Tuuli Lähdesmäki, Priscilla C.C.A. Heynderickx, Albin Wagener \& Sylvain M.F. Dieltjens

\begin{abstract}
Intercultural Cities - a joint initiative launched in 2008 by the European Commission and the Council of Europe - aims to develop a model supporting intercultural integration within diversified urban communities. This article examines, using methods of applied linguistics and discourse analysis, how intercultural urban policy is linguistically produced in the initiative. The examination indicates that the intercultural urban policy in the initiative is 'negative politics': the policy rhetoric commonly outlines the content of interculturalism by describing what is not included in it and what the policy is not about. The language used in the intercultural urban policy rhetoric presents the coexistence of distinct cultures as a problematic and conflicting issue. This contradicts the fundamental principle of the policy, which aims for co-operative and positive encountering between people in an urban environment.
\end{abstract}

\section{Keywords}

Interculturalism, urban policy, language, discourse analysis, negations, negativity

\section{Introduction}

In recent decades, Europe has become more and more diversified due to increasing pluralism resulting from global cultural flows, new means of communication, immigration, EU 
enlargement, etc. In political discourse, the diversification of societies has often been considered a positive opportunity that enriches the societies. Yet on the other hand, the problems - or challenges - generated by the multilevel diversification of the societies have also been discussed, as well as various means for tackling them. European societies have sought to govern their increasing ethnic, linguistic, religious and cultural diversity through national diversity policies, which have ranged from multiculturalism to integration and from transnationalism to assimilation (Wiesand et al. 2008). In addition, European political organisations, such as the European Union and the Council of Europe (CoE), have reacted to the diversification and the societal changes and challenges it has entailed. Indeed, diversity has become one of the key words in policy rhetoric at the European level. Besides being a popular key word or slogan, it has become an important domain of governance (Lähdesmäki \& Wagener 2015).

The interrelations between the urban environment and the opportunities, challenges and problems embedded in diversification processes have been recently discussed much in academia (e.g., Buradyidi 2000; Low, Taplin \& Scheld 2005; Sandercock 1998; Wood \& Landry 2008). Scholars have examined how cities and their urban environments should be developed in order to foster and promote fruitful and positive encounters of diverse people and cultural fluxes (Lähdesmäki 2014). Ulrike Hanna Meinhof and Anna Triandafyllidou (2006: 13) state that cities as 'focused urban environments' offer better cognitive tools than nations or states for re-imagining the new interdependencies and flows of contemporary societies. According to them, the contemporary urban realities in European cities provide a landscape for intercultural encounters and flows of immigrants to develop new forms of cultural expression that transcend the boundaries of the 'national' and the 'ethnic' and create new types of artistic expression, new cultural and commercial networks for art products, and 
eventually new realities of cultural diversity and cosmopolitanism (Meinhof \& Triandafyllidou 2006: 15). However, uses of urban space are always contested and its meanings are constantly negotiated.

In European urban reality, cities are often considered as the arena through which diversity can be governed. Cities have also been at the focus of the diversity policies of European organisations: cities (rather than counties, regions or states) appear to be the most appropriate level where new forms and types of participatory and inclusive policy processes can be designed and implemented (Council of Europe 2013: 28). Cities have been emphasised as spaces which should foster formal and informal encounters and mobilise citizens in issues of common interest that cut across ethnic and social boundaries (Khovanova-Rubicondo \& Pinelli 2012: 14) while setting out conditions for participatory and open-ended engagement to sustain micro publics of negotiation (Amin 2002).

In the most recent decade, European organisations have sought to rethink and renew their political rhetoric on governing diversity. The EU has promoted the idea of 'intercultural dialogue', e.g. in A European Agenda for Culture in a Globalising World (2007). The same idea is emphasised in the 'White Paper on Intercultural Dialogue' published by the CoE in 2008. Its aim is to provide practical suggestions for increasing intercultural dialogue as a response to various problems diversified European societies are currently facing. Attempts to govern diversity have also been put into practice in European-level urban initiatives. The European Commission's and the CoE's joint initiative, Intercultural Cities (ICC) - which was launched in the run-up to the White Paper on Intercultural Dialogue and the European Year of Intercultural Dialogue (2008) - sought to develop a model supporting intercultural integration within diversified urban communities. However, previous studies on the political rhetoric of the CoE (see Lähdesmäki \& Wagener 2015) have indicated how European official policy 
documents link ethnic, national, cultural and religious communities to ways of fragmenting societies instead of pointing out the way such communities may give meaning to the social life of people belonging to them.

The aim of this article is to examine the policy language of the ICC initiative as an explicit and implicit strategic device in order to understand the problematics involved in discussing and governing diversity. The main research question of the study is: How is intercultural urban policy linguistically produced in the ICC initiative? This question is explored in this article with quantitative and qualitative discourse analysis applying theoretical points of view from the intersection of applied linguistics, cultural studies and cultural policy research. This article proceeds from a description of the data, methods and their theoretical framework to an analysis and a discussion of the results in the context of the conceptual transformation of urban diversity policies in Europe.

\section{Theoretical Framework: Focus on Negations and Negativity}

Politics and policies are about theories and practices of influencing other people (Mouffe 2005): they aim to improve conditions and practices that are perceived by policy-makers as inadequate, deficient, malfunctioning or problematic. The heterogeneity of governing bodies and governed people produces tensions in all policy-making processes. Thus, policy discourses often contain argumentation based on negations of previous policies and/or criticism of their creators and impacts. The unintentional use of negations and negative linguistic expressions influence the policy discourse and its contents. However, negations and

negative expressions can also be used as strategic instruments in communication. The 
previous research on negations comprises diverse approaches to the use of negations and negativity in human interaction and suggests various impacts that negations and negativity have on the interplay between 'senders' and 'receivers'.

In scholarly literature, there are generally two views on the effect of negations on listeners or readers. The so-called narrow-scope view claims that the sole function of negations is to deny propositions (Evans et al. 1996 in Prado \& Noveck 2007) without any further consideration. In the search-for-alternatives view, negation processing is viewed as 'a guide to making a negated object the basis for a search among cases that can instantiate the negated object, i.e., 'the many things' that the denied proposition can be' (Prado \& Noveck 2007: 312). The results of matching experiments carried out by Prado and Noveck (2007) favour the narrow view, viz. that the participants' reaction to the negation does not go beyond denying the object or proposition.

Research on negations has been carried out in various linguistic sub-disciplines, such as morphology (e.g., Ambridge 2013; Anscombre 1994; Cartoni \& Lefer 2011), pragmatics (e.g., Baltazani 2006; Beltran, Orenes \& Santamaria 2008; Autry \& Levine 2012) and rhetorics/stylistics (e.g., Azer 1985; Vermeiren 1994). In addition, negations have been the topic of research in specific domains, such as first and second language acquisition (e.g., Drozd 1995; Eskildsen 2012), medical discourse (e.g., Burgers, Beukeboom \& Sparks 2012; Rokach, Romano \& Maimon 2008), aphasia (e.g., Jou 1988; Juncos-Rabadan 1992) and discriminatory discourse (e.g., JanMohamed 1990; Beukeboom, Finkenauer \& Wigboldus 2010). However, a search of online databases to find papers on the strategic use of negations yielded very few results. Negations are usually not the main focus of studies or they are used as one of the elements in the analysis of a different topic. Fløttum (2010), for example, uses negation particles as one of the linguistic markers of polyphony in EU discourse. Interesting 
is the research done by Beukeboom et al. (2010), who in their four studies found consistent evidence for their prediction 'that the use of negations is a source of bias that reflects and transmits a speaker's prior assumptions and expectancies about other people' (Beukeboom et al. 2010: 988).

The political language in administrative documents not only describes the reality of policies, but also participates in their production. Several scholars have investigated European politics and policies by emphasising narration, rhetoric, discourse and the use of language as a space for both conscious and unconscious production of meaning (Christiansen, Jorgensen \& Wiener 2001; Light \& Young 2009; Risse 2004; Rosamond 1999). As Diez (2001: 88) argues, the history of the European Union, with its agreements, declarations, directives and decisions, can be even perceived as a broad collection of speech acts. The effect of negations and negativity in European politics and policy discourse needs to be further analysed.

\section{Data and Methods}

In 2008, the CoE launched the ICC initiative as a pilot project with 11 cities from 11 European states in order to 'examine the impact of cultural diversity and migration from the perspective of Europe's cities and to identify strategies and policies which could help cities work with diversity as a factor of development' (Wood 2009: 17). At the end of the pilot phase in 2010, a second group of cities joined the initiative. At the moment, the initiative includes 26 cities. The ICC initiative includes an innovation in the policy discourse on governing diversity. The concept of the 'intercultural city’ originates in a study carried out by the British think tank Comedia, which has analysed the links between urban change and 
cultural diversity with the aim of providing tools to manage diversity in urban contexts (Wood \& Landry 2008). 'The intercultural cities approach' used in the ICC initiative seeks to advocate respect for diversity and pluralistic identities in the city. As Khovanova-Rubicondo and Pinelli (2012: 14) state in their assessment for the CoE:

it [the intercultural cities approach] promotes the vision of a city where informal encounters between residents with different cultural and ethnic background is easy and facilitated by the design of urban spaces and institutions. It aims at promoting open spaces of interaction, which will help breaking diversity fault lines, sustaining trust and social cohesion and facilitating the circulation of ideas and creativity.

The launch, development and functioning of the ICC initiative has produced various policy documents, such as policy briefs and thematic papers on intercultural urban policies, and diverse data about the member cities of the initiative. A key policy document of the initiative is the report 'Intercultural Cities: Towards a Model for Intercultural Integration' (2009) which introduces the main policy aims, background, rationale, urban strategies and examples of the implementation of the ICC initiative. The report consists of three subsections: 'The challenge', 'Reality check' and 'Evidence of success'. In the first subsection, the background and rationale of the intercultural cities policy and strategy per se are described. This subsection contains, amongst others, a comparison of different points of view on diversity and examples of the intercultural cities approach. In the second subsection, the indicators for an intercultural city are discussed and illustrated with ten pilot cities. The third subsection describes the positive outputs of the strategy introduced in the report. 
The book-like, colourful and easily approached 124-page report is edited by Paul Wood and published by the CoE. The report has been produced in co-operation with tens of authors who have contributed to the writing of the texts in it or have provided theoretical or technical support, advice or criticism. The authors range from urban managers and officials from the pilot cities to representatives of the CoE and the European Commission. Various well-known European urban policy experts are introduced as contributors to the report. The report reflects on and refers to other policy documents and papers that support its points of view and main arguments. Although the report says it does 'not necessarily reflect the official policy of the Council of Europe', the policy context of the initiative - being one of the CoE's official cultural actions - and the manner in which the initiative and its policy documents are promoted, e.g., on the web site of the CoE, discursively frame the report as the policy discourse of the CoE. All reports and studies commissioned by the CoE and the EU include similar reserves.

The report has been chosen as the data of this analysis due its centrality in the outlining of the policy of the initiative. Since the report gives advice on how to improve a social situation that is considered to be deplorable and unfavourable, it constitutes interesting material for an examination of the strategic use of negations and negative concepts in the policy discourse. The following excerpt from the Foreword illustrates this claim:

Unfounded myths and prejudices about minorities need to be dismantled, and certain existing civic systems and strategies must be challenged if they are to promote equality of access, participation and opportunity. (Palmer 2009: 11; emphases in the quotation by the authors) 
Our analysis of the report follows a systemic model of discourse analysis employing a methodological approach based on cognitive linguistics, semantics and pragmatics. The model implies that readers and/or receivers of discourses are submitted to what Maillat and Oswald (2009) are calling shallow processing: readers and/or receivers only perceive what is 'at the tip of the discursive iceberg'. In this perspective, readers, thus, lean on cognitive shortcuts in order to save energy and facilitate the coherence of understanding given messages by using ad hoc concepts in a spirit of cognitive comfort. However, only perceiving the 'tip of the discursive iceberg' does not mean that the rest of the 'iceberg' does not have any effect on the readers/perceivers. The meanings of discursive 'icebergs' as a whole are formed on the bases of the interpretations that readers/perceivers make of the 'tips' they perceive. In this sense, it is crucial to investigate the impact of a discourse by looking for discursive clues that can show which effects may be carried out upon readers/receivers, and, thus, unveiling messages that may sometimes be contradictory. In response to this aim, we conducted semantic and pragmatic analyses of the data through three specific methods:

- First, the text in the report was analysed using a bottom-up approach in which all negation elements were marked: prefixes (e.g. un-), suffixes (e.g. -less), particles (e.g. not), prepositions (e.g. without) and adverbs (e.g. never). All instances of negation elements were analysed in their semantic context. To analyse words with negative meaning, frequency and collocation software TextSTAT was used.

- Secondly, the data were investigated by applying Galatanu's (2009) semantics of argumentative possibilities model (SAP model), which indicates how readers/receivers may use semantically loaded representations in given topical clouds to create (or recreate) a cohesive discursive environment. Galatanu's works rely heavily on linguistic 
and semantic analyses, thus allowing investigation of what lies behind the first glimpse permitted by shallow processing.

- Thirdly, Cap’s $(2013,2014)$ proximisation model (STA model - for spatial/temporal/axiological analysis), inspired most of all by pragmatic approaches, was utilised in the analysis. The model seeks to indicate how spatial, temporal and axiological proximity have an effect on how readers perceive and interpret discourses and recreate their meanings.

The methods and their theoretical points of departure centre around what Cap (2014) calls 'the discourse space’; a cognitive and symbolic distance organised within discourse in order to reach the reader/receiver:

Proximization theory acknowledges the primacy of spatial cognition in language use and the construction of discourse. [...] Within this mental space, not only entities, but also events are observed and organized relatively to a 'deictic center’. (Cap 2014: 18.)

In this article we assess that the weight of the deictic centre is based on a dialogue between European organisations (the $\mathrm{CoE}$ and the EU) and European citizens, bringing both entities together in a semantically charged symbolic space where both are expected to work for the well-being and promote the evolution of a European polity, particularly by fostering intercultural dialogue and social exchange in general. As our analysis indicates, unwillingness to embrace the discourse of the CoE/EU can be interpreted in the semantic frame of the data 
as an indication that unwilling European citizens are not 'worthy' of the 'European project' promoted by the EU and the CoE.

\section{Analysis}

\section{Negation Elements: Quantitative Results}

The text in the Intercultural Cities: Towards a Model for Intercultural Integration contains 7,81\%o negation elements (adverbs, particles prepositions, prefixes, suffixes). Compared with other kinds of texts analysed with the same method, such as transcripts of debates in the Flemish Parliament: 13,63\%o (Vermeulen 2010) and hospital websites on palliative care: 12,3\% (Bremen 2014), the number indicates a generally moderate use of negations. Table 1 shows how the negations are divided among the subsections. The subsections 'Evidence of success' and 'Conclusion' have the lowest per mille values, which is a first indication of the strategic use of the negations.

(Table 1 near here)

In the analysis, the number of negations in each paragraph of the subsections was separately examined. The introductions to 'Examples of intercultural approaches in European cities' and 'Pilot intercultural cities' and the paragraph 'Establishing partnerships and alliances' do not contain negation elements. The two negations in the paragraph 'Building an intercultural agenda for cities' are included in a cited definition of an intercultural city. The report includes 
four paragraphs which contain significantly more negation elements than the report's average (Table 2). The first three are a part of the subsection 'The challenge' and the fourth is a part of 'Reality check'. In the table where the different urban policy approaches to diversity (Wood 2009: 23-24) are summarised and contrasted, the per mille value of the negations is as high as 58,99 .

(Table 2 near here)

\section{Negation Elements: Qualitative Results}

Analysis of the textual context of negation elements reveals distinct usages. Firstly, the negation elements are often used in combination with words with a negative meaning. Their function is to deny the negative aspects and give the statement a positive meaning (examples 1 and 2). A comparable effect is achieved in sentences with double negations (example 3).

1) A good intercultural vision is one that inspires and motivates and is not couched in bureaucratic language [...] (Wood 2009: 34)

2) The city would also have made a formal statement sending an unambiguous public statement of its commitment to intercultural principles and would be actively engaged in persuading other key stakeholders in the city to do likewise. (Wood 2009: 48) 
3) A mapping of intercultural issues should not ignore the needs and aspirations of the indigenous population experiencing socio-economic disadvantage who may also feel discriminated against and marginalised. (Wood 2009: 32)

Secondly, the negation elements occur in sentences in which oppositions are expressed (often by 'but'; example 4). The combination with concessive sentences has similar effects (example $5)$.

4) How can the city let local people know that being 'intercultural' is not just a word but a new way of doing things? (Wood 2009: 49)

5) However, it is not the intention of the project to use the Index for the crude 'ranking' of cities. Rather it should [...] (Wood 2009: 79)

Thirdly, the negative elements are often minimised by counteracting words in the same sentence (examples 6 and 7).

6) Is there a joint strategy for dealing with tension and misinformation in the community? (Wood 2009: 66)

7) It has focused particularly on educational improvement as the basis for tackling poverty and social exclusion in its multi-ethnic community. (Wood 2009: 103) 
Examples 6 and 7 also demonstrate how negation elements in the report occur in enumerations with words with a negative meaning, such as ‘tension' (6) and 'poverty’ (7). Example 8 illustrates this technique in more detail.

8) The development of segregation (whether through accident or design) and the lack of mutual knowledge and empathy between cultures and factors such as economic uncertainty, rivalry for resources, extremist politics or religion, sensationalist media and the impact of world events can all combine to create turmoil in a city. (Wood 2009: 29)

Fourthly, example 8 shows how negations are used without modification or counteraction when the report describes unwanted situations - usually situations that will be rectified by the intercultural cities strategy put forward in the rhetoric of the report. The table on pages 23-24 in the report compares five intercultural policies named as non-policy, guest worker policy, assimilationist policy, multicultural policy and intercultural policy. Table 3 contains one row from the original table. To describe the first three policies, which are considered unfavourable in the report, negations without corrections are introduced. For the fifth policy, the positive element is accentuated by contrasting it with the negation of a negative element ('functional not symbolic use of space').

(Table 3 near here) 


\section{Semantic elements}

A semantic analysis of markers of negation brought to the fore the way negativity in general is handled in the report. The analysis was conducted in two phases. Firstly, we identified the key words and concepts most frequently used in relation to the topic of the report. These key words and concepts were: 'prevention', 'national', 'urban', 'intercultural', 'culture/al', 'migrants/tion', 'mediation', ‘violence’, ‘diversity’, ‘inevitability’, ‘management', ‘dialogue’ and 'communities'. These concepts form the rhetorical bases on which the system of discourse is created throughout the report. Secondly, we examined how the topic of the report is linked to negation and/or negativity by a means of linguistic clues that show a negative side of the semantic coin. Therefore, we selected for closer analysis a list of negative semantic areas recurring in the report: 'conflict(s)', 'problem(s)', 'tension(s)', 'racism/racist', 'violence/violent' and 'concern(s)/concerned/concerning'. The analysis focused on the cotextual occurrences of these semantic areas in order to understand the possible negative links between them and the central key words and concepts used in the report. A triangulation of the methods used gave interesting results in terms of links between overall negative or 'semantically negatively charged' terms and the central concepts promoted in the report. Table 4 indicates the occurrences supported by the selected negative semantic areas in the report.

(Table 4 near here)

The results indicate that 'conflicts' remain the most quoted negative semantic area in the report. The result reflects the aim of the intercultural cities strategy: conflicts are perceived as 
a problem that should be overcome by heavily relying on and practicing an intercultural dialogue. The second semantic area, 'problems', comes very close to 'concerns'. The occurrence of the three remaining semantic areas is relatively moderate compared with the three first ones.

Yet the most important result of our analysis is the way these semantic areas are combined with the central key words and concepts that form the system of discourse in the report. The key words and concepts which had more than 10 occurrences linked to the negative semantic areas described above were selected for closer examination: 'intercultural' (33 occurrences), ‘culture/al' (16 occurrences), ‘communities' (13 occurrences) and ‘migrants/tion’ (11 occurrences).

(Figure 1 near here)

Unsurprisingly, 'intercultural' is heavily linked to 'conflict/conflicts' (with 16 co-textual occurrences), followed by 'tension/tensions' (6 co-textual occurrences) and 'problem/problems' (4 co-textual occurrences). The topic cloud of 'intercultural conflicts' has been widely studied and it has been perceived as being often used to overcome cultural differences and to show why such differences matter in daily life (Wagener 2014). Intercultural Cities: Towards a Model for Intercultural Integration makes no exception: 'intercultural' is rarely linked to 'racism' or 'violence'. In the report, a more softened version of social discrepancy is instead used in order not to produce an essentialisation of the social matter. In other words, speaking of 'intercultural conflicts' shows the complexity of social interactions without emphasising terms that could be hard to overcome: a conflict can be solved or managed, while 'racism’ or ‘violence’ remain harder to handle. 
(Figure 2 near here)

Unlike its semantic relative, 'culture/cultural' shows a different distribution of links with negative terms: 'conflicts' (6 co-textual occurrences) and 'concerns/ed/ing' (4 occurrences) come first, closely followed by 'problem/s' (3 co-textual occurrences). While the link between 'culture/al' and 'conflict/s' can be explained on the same bases as the links between 'intercultural' and 'conflict/s', the weight of 'concerns' and 'problems' linked to 'culture/al' is more puzzling; it seems that while the very idea of interculturalism may help overcome conflicts in social relations, culture per se is more essentially linked to problems and concerns. In the report, there is no actual relation of cause or effect between these semantic areas, yet 'culture' presents a more important relation to what may challenge societies throughout Europe. In other words, while interculturalism is presented in the report as the key to developing and improving European communality, distinct (ethnic/national) cultures as isolated entities are sketched out as a source of worries and concerns for European societies and the EU.

(Figure 3 near here)

In Intercultural Cities: Towards a Model for Intercultural Integration, 'communities' are mostly linked to 'conflicts' (6 co-textual occurrences) and 'concerns' (4 co-textual occurrences). While the number of co-textual occurrences generally stays relatively low in the report, 'communities' is, however, commonly linked to overall negative terms (13 times). The result stresses the fact that distinct and differentiated groups of people are considered as 
representing a threat to European societies or the 'European project', as is often explicitly or implicitly brought to the fore in official European policy rhetoric. Similarly, the rhetoric of the report often pictures 'communities' as sources of conflicts, tensions or concerns, even though the primary aims of the text may have positive aspirations, as the following example (9) shows:

9) A mapping of intercultural issues should not ignore the needs and aspirations of the indigenous population experiencing socio-economic disadvantage who may also feel discriminated against and marginalised. There is wide evidence that these groups can feel 'left behind' in a focus on minority communities and this can exacerbate intercultural tensions. (Wood 2009: 32-33)

Although all 'communities' are not presented in the report through negative topic clouds, 'communities' are, however, often presented as a potential source of problems for intercultural cities.

(Figure 4 near here)

An analysis of 'migrants/migration' produces the most interesting results, albeit through a small amount of co-textual occurrences, since this semantic area is almost exclusively linked to 'concerns/concerned/concerning' in a negative manner (6 co-textual occurrences), leaving 'problem', 'conflict', 'tensions' and 'racist' far behind. As in the case of other key concepts, 'migrants/migration' is not only shown in a negative manner in the report, but when it is shown it really stresses various 'concerns'. Although the report seeks to foster intercultural 
dialogue and promote the inclusion of 'newcomers' to the urban social space, the concept of migration (meaning mostly non-European citizens settling in European cities) addresses issues of concern that are underlined throughout the report, as the following example (10) indicates:

10) Another programme sends successful migrants to meet employers and convince them that migrant employees are not a risky proposition. (Wood 2009: 60)

As example 10 shows, even when migration and migrants are positively represented, they can be, however, related to fundamental social risks.

\section{Discussion: Conceptual Transformations in European Urban Diversity Policy}

The $\mathrm{CoE}$ is a prominent agency in the development of discourses on culture, identity and diversity in Europe (Sassatelli 2009: 43). Its rhetorical formulations and areas of interest have commonly been absorbed into the EU's political discourses and goals with a short delay, particularly in questions related to culture (Patel 2013: 6; Sassatelli 2009: 43, 59). Promoting the coexistence of different cultures in European societies has been in the interests of the CoE since its beginning. The CoE has actively promoted the idea of cultural diversity along with a common European identity and unity in Europe. The idea of 'unity in diversity' in Europe an idea which was later adopted as the official slogan of the EU - was brought to the fore in the CoE's Resolution on the European Cultural Identity already in 1985. The diversity rhetoric of the CoE was transformed in the 1990s, when the idea of multiculturalism was 
adopted into discussions on European identity along with the declaration of a Multicultural Society and European Cultural Identity (1990). The Declaration on Cultural Diversity (2000) brought a broader aspect to the diversification processes in Europe by discussing diversity in relation to information technologies, globalisation and trade policies.

In recent years Europe has faced a political backlash against multiculturalism (Bauböck 2008: 7; Modood \& Meer 2012: 190). In addition, the concept of multiculturalism has been a topic of many recent critical discussions and analyses in academia. It has been criticised e.g., for emphasising boundaries instead of their blurring, and for focusing mainly on ethnic and national issues instead of paying attention to the multisectional diversity in societies (e.g., Taylor 2012; Rodríguez-García 2010). The critics have instead discussed contemporary diversity and its governance using the term interculturalism, emphasising how the current age of globalisation and 'super diversity' needs an interdisciplinary approach to diversity to 'chang[e] mindsets by creating new opportunities across cultures to support intercultural activity' (Cantle 2012) and to enable 'cultures to have currency, to be exchanged, to circulate, to be modified and evolve' (Sze \& Powell 2004: 1) in society.

The political and societal debates over multiculturalism in the most recent decade have influenced the current diversity politics and policy rhetoric of the CoE and the EU. Several recent EU and CoE policy documents have participated in and speeded up the shift in diversity politics in Europe by emphasising 'interculturalism' and 'intercultural dialogue' instead of multiculturalism as a core focus of the policy rhetoric. The ICC initiative is an example of this shift: the focus of the policy discourse has been turned to encountering and communication between diverse people in diversified societies. Several scholars have, however, emphasised that the concepts and policy rhetoric of interculturalism and multiculturalism are discursively fluid and it is difficult to draw any clear or stable 
demarcation between the two (Levey 2012; Modood \& Meer 2012; Wieviorka 2012). As Modood and Meer (2012) have pointed out, the qualities, such as encouraging communication, recognition of dynamic identities, promotion of unity and critique for illiberal cultural practice, that are often used to promote political interculturalism are equally important (and on occasion foundational) features of multiculturalism.

Interculturalism is both a political innovation and a sign of a conceptual change in urban diversity policies (Lähdesmäki \& Wagener 2015). However, the fluid and vague content of the concept makes it an ambivalent policy whose essence is difficult to outline. This vagueness is also a result of the language used in its policy rhetoric. As the analysis of the policy report of the ICC initiative indicates, the policy rhetoric often outlines the content of interculturalism by describing what is not included in it and what the policy is not about. The ambiguity of the intercultural urban policy challenges its implementation in today's superdiversified societies in which diversity itself is broad, multidimensional and fluid (Blommaert \& Rampton 2011; Vertovec 2007).

\section{Conclusions}

Diversification of European societies is often discussed in relation to social problems and potential conflicts and tensions between distinct ethnic, national, cultural or religious communities. In order to tackle these real or imagined problems, conflicts and tensions, politicians, authorities and scholars have developed various social initiatives, programmes and models which have been put into practice with varying results. The ICC initiative is one of these attempts which seek to improve social relations between diverse communities. In the 
initiative, urbanity functions as the frame for its social policy: local communities, everyday life and people’s living neighbourhoods are its focus.

The analysis of the key policy document of the ICC initiative brought out five main findings. The motivation for fostering and promoting intercultural dialogue is embedded in the rhetoric used in diversity policies. This rhetoric can be perceived as the 'tip of a discursive iceberg': in the first place it appeals to a sense of justice, equality, care and social responsibility, but a deeper study reveals the meanings and values related to it 'below sea level'. (1) The selection of analytical methods which combined discourse analysis and applied linguistics indicates how the meanings of the objects of politics in the intercultural cities approach are linguistically produced. (2) The lexical and semantic analysis of negations and negative expressions enabled a perception of the interdependent and co-productive mechanisms of concepts in the policy rhetoric, indicating how the use of language and conceptualisation is value-loaded and ideological.

Our analysis brought to the fore that the intercultural urban policy in the ICC initiative is 'negative politics'. (3) The results reveal the vague and ambivalent nature of the policy rhetoric: the authors of the ICC policy documents have difficulties describing what the intercultural urban policy really is. It is instead described through what it is not or what it should avoid. (4) The language used in the analysed intercultural urban policy rhetoric outlines interculturalism and the coexistences of cultures as a problematic and conflicting issue. This is contradictory to the fundamental principle of the policy, which aims for cooperative and positive encountering between people in an urban environment. (5) In the policy rhetoric of the ICC initiative, diversity per se is discussed in an extremely narrow sense. Even though the practical guide of the ICC initiative states that good intercultural policy practices 'should reach beyond the issues of migration and ethnic diversity to embrace 
all aspects of difference in contemporary urban communities' (Council of Europe 2013: 71), the common subjects of the rhetoric of interculturalism are the migrant and ethnic groups. In the rhetoric of the initiative, these groups often narrow to mean non-European, non-white, non-Christian and non-educated migrants.

Even though the ICC initiative focuses on locality, its policy discourse has been formed at the European level. European-level policy documents, such as the White Paper on Intercultural Dialogue, poorly recognise the societal or historical differences between societies in Europe and commonly offer unified - and Western European - views on the governance of diversity (cf. Lähdesmäki \& Wagener 2015). The ERICarts report for the European Commission states that the diversity policies formulated on the European level do not seem to reach the national or local levels and are incorporated in a heterogeneous manner in national legislations or policies (Wiesand et al. 2008: iv). The report claims that it cannot be realistically expected that one single model of governing diversity which encompasses all national approaches to intercultural dialogue could be formulated and applied in Europe (Wiesand et al. 2008: v). The claim reflects the fact that there are different kinds of diversities in Europe. Different historical, political and social conditions have produced distinct 'diversity structures’ (Saukkonen 2007: 41-54) in European societies. Thus, suggestions of common and generic diversity policies for Europe inevitably simplify the idea of diversity in Europe and produce new hierarchies between the subjects and objects of these diversity policies.

Our study suggests that the different historical, political and social conditions of diversities and the intersectionality of social and cultural categories need to be taken into better consideration in policy-making in today’s 'super-diverse' European societies. Politics is made through language and discourse: the use of language produces subjects and objects and 
their - often hierarchical - relations. More cautious use of language in the policy discourse would produce more accurate diversity policies and dissolve the hierarchical and value-loaded meanings often unintentionally included in the discourse. Instead of approaching the problems in interaction and social relations from the point of view of ethnic diversity and dialogue between ethnically, nationally, culturally or religiously distinct communities, an improvement of the social relations and interaction between diverse people could be discussed by emphasising in general the promotion of well-being, employment and social inclusion in the society (cf. Lähdesmäki 2014).

\section{References}

Ambridge, B. 2013. How do children restrict their linguistic generalizations? An (un-) grammaticality judgment study. Cognitive Science 37 (3): 508-543.

Amin, A. 2002. Ethnicity and the multicultural city: living with diversity. Environment and Planning A 34 (6): 959-980.

Anscombre, J.C. 1994. L'Insoutenable légèreté morphologique du préfixe négatif in- dans la formation d'adjectifs. LINX 5: 299-321.

Autry, K.S. \& W.H. Levine. 2012. Activation of negated and non-negated entities. Journal of Pragmatics 44 (11): 1474-1485. 
Azer, H.A. 1985. The expression of negation in Egyptian colloquial Arabic (ECA). Studies in African Linguistics (supplement) 9: 15-18.

Baltazani, M. 2006. Intonation and pragmatic interpretation of negation in Greek. Journal of Pragmatics 38 (10): 1658-1676.

Bauböck, R. 2008. Beyond culturalism and statism. Liberal responses to diversity. Eurosphere Working Paper Series, online working paper 6. http://eurospheres.org/files/2010/08/plugin-

Eurosphere_Working_Paper_6_Baubock.pdf

Beltran, D., I. Orenes \& C. Santamaria. 2008. Context effects on the spontaneous production of negation. Intercultural Pragmatics 5 (4): 409-419.

Beukeboom, C.J., C. Finkenauer \& D.H.J. Wigboldus. 2010. The negation bias: When negations signal stereotypic expectancies. Journal of Personality and Social Psychology 99 (6): 978-992.

Blommaert, J., \& B. Rampton. 2011. Language and superdiversity. Diversities 23 (2): 1-22.

Bremen, I. 2014. Palliatieve zorg: waarover en hoe informeren Nederlandse en Vlaamse academische ziekenhuizen op hun websites? PhD diss., Katholieke Universiteit Leuven.

Buradyidi, M. ed. 2000. Urban Planning in a Multicultural Society. Westport: Praeger. 
Cap, P. 2013. Proximization theory and critical discourse studies: A promising connection? International Review of Pragmatics 5 (2): 293-317.

Cap, P. 2014. Applying cognitive pragmatics to critical discourse studies: A proximization analysis of three public space discourses. Journal of Pragmatics 70: 16-30.

Cantle, T. 2012. Interculturalism: For the Era of Cohesion and Diversity. Basingstoke: Palgrave Macmillan.

Cartoni, B. \& M.A. Lefer. 2011. Negation and lexical morphology across languages: Insights from a trilingual translation corpus. Poznan Studies in Contemporary Linguistics 47 (4): 795843.

Christiansen, T., K.E. Jorgensen, \& A. Wiener ed. 2001. The Social Construction of Europe. London: Sage.

Council of Europe. 2013. The Intercultural City Step by Step. Practical Guide for Applying the Urban Model of Intercultural Integration. Strasbourg: Council of Europe Publishing.

Diez, T. 2001. Speaking 'Europe': The politics of integration discourse. In The Social Construction of Europe, ed. T. Christiansen, K.E. Jörgensen \& A. Wiener, 85-100. London: Sage. 
Drozd, K.F. 1995. Child English pre-sentential negation as metalinguistic exclamatory sentence negation. Journal of Child Language 22 (3): 583-610.

Eskildsen, S.W. 2012. L2 negation constructions at work. Language Learning 62 (2): 335372.

Fairclough, N., \& R. Wodak. 1997. Critical discourse analysis. In Discourse as Social Interaction, ed. T.A. Van Dijk, 258-284. London: Sage.

Fløttum, K. 2010. EU discourse: Polyphony and unclearness. Journal of Pragmatics 42 (4): 990-999.

Galatanu, O. 2009. L’analyse du discours dans la perspective de la sémantique des possibles argumentatifs: les mécanismes sémantico-discursifs de construction du sens et de reconstruction de la signification lexicale. In L'analyse linguistique des corpus discursifs. Des théories aux pratiques, des pratiques aux théories, ed. N. Garri \& J. Longhi, 49-68. Clermont-Ferrand: Presses Universitaires Blaise-Pascal.

Garric, N., \& J. Longhi. 2013. Atteindre l'interdiscours par la circulation des discours et du sens. Langage et Société 144 (2): 65-83.

JanMohamed, A R. 1990. Negating the negation as a form of affirmation in minority discourse: The construction of Richard Wright as subject. In The Nature and Context of 
Minority Discourse, ed. A.R. JanMohamed, \& D. Lloyd, 102-123. New York: Oxford University Press.

Juncos-Rabadan, O. 1992. The processing of negative sentences in fluent aphasics: Semantic and pragmatic aspects. Brain and Language 43 (1): 96-106.

Khovanova-Rubicondo, K., \& D. Pinelli. 2012. Evidence of the economic and social advantages of Intercultural Cities approach. Meta-analytic assessment for the Council of Europe. Strasburg: Council of Europe. http://www.coe.int/t/dg4/cultureheritage/culture/Source/Cities/Review.doc.

Lähdesmäki, T. 2014. The role of space in the politics of intercultural dialogue. In Cultural Encounter. The Mosaic of Urban Identities, eds. E.-N. Burdușel, O. Matiu, D. Preda \& A. Tomuș, 28-42. UNeECC Forum vol. 6. Sibiu: University Network of the European Capitals of Culture.

Lähdesmäki, T., \& A. Wagener. 2015. Discourses on governing diversity in Europe: Critical analysis of the White Paper on Intercultural Dialogue. International Journal of Intercultural Communication 44: 13-28.

Levey, G.B. 2012. Interculturalism vs. multiculturalism: A distinction without a difference? Journal of Intercultural Studies 33 (2): 217-224. 
Light, D., \& C. Young. 2009. European Union enlargement, post-accession migration and imaginative geographies of the 'New Europe': media discourses in Romania and the United Kingdom. Journal of Cultural Geography 26 (3): 281-303.

Low, S., D. Taplin, \& S. Scheld ed. 2005. Rethinking Urban Parks: Public Space \& Cultural Diversity. Austin: University of Texas Press.

Maillat, D., \& S. Oswald. 2009. Defining manipulative discourses: The pragmatics of cognitive illusions. International Review of Pragmatics 1 (2): 348-370.

Meinhof, U.H., \& A. Triandafyllidou. 2006. Transcultural Europe: An introduction to cultural policy in a changing Europe. In Transcultural Europe. Cultural Policy in a Changing Europe, ed U.H. Meinhof \& A. Triandafyllidou, 3-23. Basingstoke: Palgrave MacMillan.

Modood, T., \& N. Meer. 2012. How does interculturalism contrast with multiculturalism? Journal of Intercultural Studies 33 (2): 175-196.

Mouffe, C. 2005. On the Political. London: Routledge.

Palmer, R. 2009. Foreword. In Intercultural Cities: Towards a Model for Intercultural Integration, ed. P. Wood, 11-12. Strasbourg: Council of Europe Publishing.

Patel, K.K. 2013. Introduction. In The Cultural Politics of Europe. European Capitals of Culture and European Union since the 1980s, ed. K.K. Patel, 1-15. London: Routledge. 
Paveau, M.-A. 2006. Les prédiscours: sens, mémoire, cognition. Paris: Presses Sorbonne Nouvelle.

Prado, J., \& I.A. Noveck. 2007. How reaction time measures elucidate the matching bias and the way negations are processed. Thinking \& Reasoning 12 (3): 309-328.

Risse, T. 2004. Social constructivism and European integration. In European Integration Theory, ed. T. Diez \& A. Wiener, 159-176. Oxford: Oxford University Press.

Rodríguez-García, D. 2010. Beyond assimilation and multiculturalism: A critical review of the debate on managing diversity. Migration \& Integration 11 (3): 251-271.

Rosamond, B. 1999. Discourses of globalization and the social construction of European identities. Journal of European Public Policy 6 (4): 652-668.

Sandercock, L. 1998. Towards Cosmopolis: Planning for Multicultural Cities. London: John Wiley.

Sassatelli, M. 2009. Becoming Europeans. Cultural Identity and Cultural Policies. New York: Palgrave Macmillan.

Saukkonen, P. 2007. Politiikka monikulttuurisessa yhteiskunnassa (Politics in a multicultural society). Helsinki: WSOY. 
Sze, F. \& D. Powell. 2004. Introduction. In Interculturalism: Exploring Critical Issues, ed. F. Sze \& D. Powell, 1-2. Oxford: Interdisciplinary Press.

Taylor, C. 2012. Interculturalism or multiculturalism? Philosophy \& Social Criticism 38 (45): 413-423.

Van Dijk, T. 2006. Discourse and manipulation. Discourse and Society 17: 359-383.

Vermeiren, H. 1994. La Rhetorique de la negation. LINX 5: 331-341.

Vermeulen, M. 2010. Negaties in de plenaire vergaderingen van het Vlaams Parlement. PhD diss., Katholieke Universiteit Leuven.

Vertovec, S. 2007. New Complexities of Cohesion in Britain: Super-diversity, Transnationalism and Civil-integration. Commission on Integration and Cohesion. Wetherby: Communities and Local Government Publications.

Wagener, A. 2014. Creating identity and building bridges between cultures: The case of 9gag. International Journal of Communication 8: 2488-2502.

Wiesand, A., I. Heiskanen, R. Mitchell, D. Cliché, M. Fisher, \& L. Marsio. 2008. Sharing Diversity. National Approaches to Intercultural Dialogue in Europe. Study for the European Commission. Bonn: European Institute for Comparative Cultural Research. 
Wieviorka, M. 2012. Multiculturalism: A concept to be redefined and certainly not replaced by the extremely vague term of interculturalism. Journal of Intercultural Studies 33 (2): 225231.

Wood, P., \& C. Landry 2008. The Intercultural City: Planning for Diversity Advantage. London: Earthscan.

Wood, P. ed. 2009. Intercultural Cities: Towards a Model for Intercultural Integration. Strasbourg: $\quad$ Council of $\quad$ Europe $\quad$ Publishing. https://www.coe.int/t/dg4/cultureheritage/culture/Cities/ICCModelPubl_en.pdf

Words: 7560 
Table 1. Number of negations in the different subsections in Intercultural Cities: Towards a Model for Intercultural Integration (2009).

\begin{tabular}{lccc} 
Subsection & Word count & Number of negations & Per mille \\
\hline Foreword & 473 & 3 & 6,34 \\
The challenge & 21217 & 173 & 8,15 \\
Reality check & 7670 & 63 & 8,21 \\
Evidence of success & 1726 & 6 & 3,48 \\
Conclusion & 656 & 3 & 4,57 \\
\hline TOTAL & 31742 & 248 & 7,81
\end{tabular}


Table 2. Paragraphs with high per mille values in Intercultural Cities: Towards a Model for Intercultural Integration (2009).

\begin{tabular}{lccc} 
Paragraph & Word count & Number of negations & Per mille \\
\hline $\begin{array}{l}\text { Different urban policy } \\
\text { approaches }\end{array}$ & 1382 & 42 & 30,40 \\
$\begin{array}{l}\text { Preparing for an intercultural } \\
\text { city strategy }\end{array}$ & 306 & 12 & 39,22 \\
$\begin{array}{l}\text { Consultation and } \\
\text { participation }\end{array}$ & 292 & 6 & 20,55 \\
Tilburg & 529 & 11 & 20,79
\end{tabular}


Table 3. Excerpt from the table displayed on pages 23-24 in Intercultural Cities: Towards a Model for Intercultural Integration (2009).

\begin{tabular}{|c|c|c|c|c|c|}
\hline & Non-policy & $\begin{array}{l}\text { Guestworker } \\
\text { policy }\end{array}$ & $\begin{array}{l}\text { Assimilationist } \\
\text { policy }\end{array}$ & $\begin{array}{l}\text { Multicultural } \\
\text { policy }\end{array}$ & $\begin{array}{l}\text { Intercultural } \\
\text { policy }\end{array}$ \\
\hline $\begin{array}{l}\text { Governance } \\
\text { and } \\
\text { citizenship }\end{array}$ & $\begin{array}{l}\text { No rights or } \\
\text { recognition }\end{array}$ & $\begin{array}{l}\text { No rights or } \\
\text { recognition }\end{array}$ & $\begin{array}{l}\text { Facilitate } \\
\text { naturalisation. } \\
\text { No ethnic } \\
\text { consultative } \\
\text { structures }\end{array}$ & $\begin{array}{l}\text { Community } \\
\text { leadership, } \\
\text { consultative } \\
\text { structures and } \\
\text { resource } \\
\text { allocation } \\
\text { ethnically- } \\
\text { based }\end{array}$ & $\begin{array}{l}\text { Encouragement } \\
\text { of cross-cultural } \\
\text { leadership, } \\
\text { association and } \\
\text { consultation. } \\
\text { Acknowledgeme } \\
\text { nt of hybridity. } \\
\text { Emphasis on } \\
\text { functional not } \\
\text { symbolic use of } \\
\text { space }\end{array}$ \\
\hline
\end{tabular}


Table 4. Occurrences of six negative semantic areas in Intercultural Cities: Towards a Model for Intercultural Integration (2009).

\begin{tabular}{lcc} 
Semantic area & Word count & $\mathbf{\%}$ \\
\hline Conflicts & 68 & 41,21 \\
Problems & 33 & 20,00 \\
Concerns & 31 & 18,79 \\
Tensions & 12 & 7,27 \\
Violence & 11 & 6,67 \\
Racism & 10 & 6,06 \\
\hline & 165 & 100,00
\end{tabular}


List of figure captions:

Figure 1. Semantic links between 'intercultural' and selected negative semantic terms in Intercultural Cities: Towards a Model for Intercultural Integration (2009).

Figure 2. Semantic links between 'culture/cultural' and selected negative semantic terms in Intercultural Cities: Towards a Model for Intercultural Integration (2009).

Figure 3. Semantic links between 'communities' and selected negative semantic terms in Intercultural Cities: Towards a Model for Intercultural Integration (2009).

Figure 4. Semantic links between 'migrants/migration' and selected negative semantic terms in Intercultural Cities: Towards a Model for Intercultural Integration (2009). 